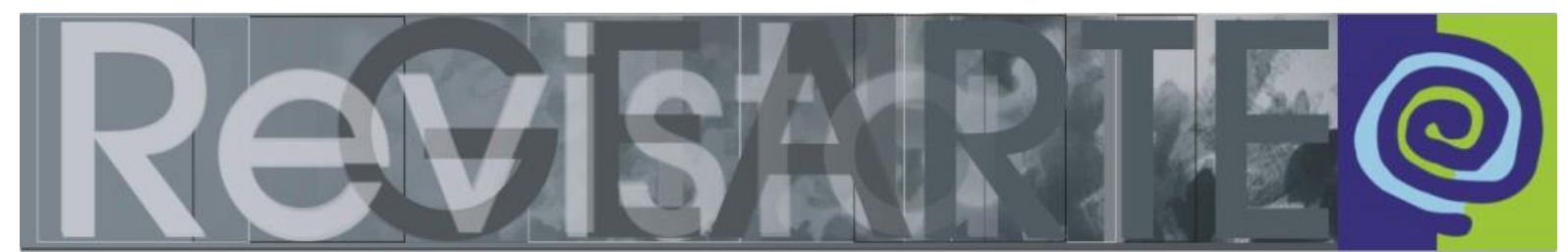

ISSN 2357-9854 | e-ISSN 2596-3198 (online)

\title{
A Arte/Educação no ambiente da escola quilombola de Mata Cavalo: cultura de diálogos e resistência
}

\author{
Cristiane Carolina de Almeida Soares \\ (Universidade Federal de Mato Grosso — UFMT, Cuiabá/MT, Brasil) \\ Regina Aparecida da Silva \\ (Universidade Federal de Mato Grosso — UFMT, Rondonópolis/MT, Brasil) \\ Michèle Tomoko Sato \\ (Universidade Federal de Mato Grosso — UFMT, Cuiabá/MT, Brasil)
}

\begin{abstract}
RESUMO - A arte/educação no ambiente da escola quilombola de Mata Cavalo: cultura de diálogos e resistência - No quilombo de Mata Cavalo, a escola é um contexto de aprendizagem rico, porém excludente, repleto de preconceito e injustiças socioambientais. Procura estimular as práticas da arte/educação. Para atender às especificidades educacionais, esta escola planeja as aulas de Arte, junto a uma das disciplinas da parte diversificada do currículo. Entretanto, as manifestações culturais ultrapassam os muros da escola, por meio da educação popular. Temos o objetivo de discutir o ensino de arte e cultura em Mata Cavalo, junto à produção artesanal e as atividades coletivas, que afrontam a hegemonia capitalista. Utilizamos a metodologia Mapa Social, para evidenciar o fortalecimento cultural da comunidade.
\end{abstract}

PALAVRAS-CHAVE:

Arte/educação. Cultura. Quilombo. Mata Cavalo. Educação popular.

ABSTRACT - Art education in the Mata Cavalo quilombola school: dialogues and experiences culture - In the Mata Cavalo quilombola community, the school is a rich but, exclusive, learning context, full of prejudice and socio-environmental injustices. It seeks to encourage art/education practices. To meet educational specificities, this school plans Art classes along with one of the disciplines in the diversified part of the curriculum. However, cultural manifestations go beyond the school walls, through popular education. We aim to discuss art and culture teaching in the Mata Cavalo, along with artisanal productions and collective activities, which confront capitalist hegemony. The Social Map methodology was used to highlight the cultural strengthening of the community.

KEYWORDS:

Art education. Culture. Quilombo. Mata Cavalo. Popular education.

RESUMEN - La educación artística en el ambiente de la escuela quilombola de Mata Cavalo: cultura de diálogos y resistencia - En el quilombo (palenque) de Mata Cavalo, la escuela conforma un contexto de aprendizaje rico, sin embargo excluyente, plagado de prejuicios, injusticias sociales y ambientales. Ahí se busca estimular las prácticas de educación artística. Para cumplir con las especificidades educacionales, esta escuela planifica e imparte clases de Arte, asociadas a una de las disciplinas de la parte diversificada de su programa de estudios. Sin embargo, las manifestaciones culturales van más allá de los muros de la escuela a través de la educación popular. Se objetiva discutir la enseñanza de arte y cultura en Mata Cavalo, asociada a la producción artesanal y a las actividades colectivas que afrontan la hegemonía capitalista. Se utiliza la metodología Mapa Social con el fin de evidenciar el fortalecimiento cultural de la comunidad.

PALAVRAS-CLAVE:

Educación Artística. Cultura. Quilombo/Palenque. Mata Cavalo. Educación popular.

SOARES, Cristiane Carolina de Almeida; SILVA, Regina Aparecida da; SATO, Michèle Tomoko. 


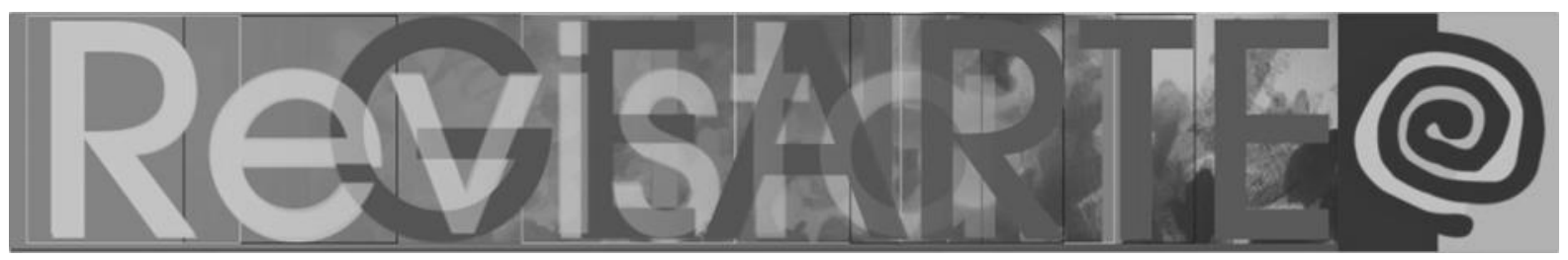

\section{Trilhando caminhos no Quilombo de Mata Cavalo}

Ao iniciar nossa caminhada em solo quilombola, abordaremos sucintamente suas origens, para evidenciar algumas particularidades. Munanga (1996) afirma que os quilombos da África, comumente originários dos povos de língua bantu, nos séculos XVI e XVII, portavam o significado de 'campo de iniciação', nos quais haviam rituais para integrar e unificar jovens que se tornariam grandes guerreiros, agregando também diversas etnias. Muitos destes quilombolas africanos vieram escravizados para o Brasil, onde passaram a constituir um novo grupo, composto pelos oprimidos que fugiam do exaustivo trabalho das senzalas e plantações, opondo-se também aos modelos ideológicos excludentes, junto a indígenas e pessoas de origem humilde. Com o fim da escravidão no Brasil, grande parte dos quilombos foram destruídos, e os que permaneceram, acabaram se distanciando da formação inicial, anteriormente focados em resistir ao escravismo colonial (LEITE, 2000).

Atualmente, estes espaços organizam a luta legítima pelos direitos dos que tiveram seus antepassados marcados pela escravidão, e que ainda sofrem injustiças e discriminações, sendo negligenciados e segregados pela atual política, racista e excludente. Neste sentido, "os quilombos contemporâneos, a exemplo de MataCavalo, mesmo tendo origens diferentes das do século XVIII, e estando economicamente empobrecidos, conservam o mesmo espírito de luta" (Castilho, 2008, p. 67).

Os quilombos da atualidade não se referem somente aos acontecimentos passados, pois atualmente representam um grupo que demanda novas políticas e ações sociais, que thes reconheçam direitos e práticas culturais. Contudo, a estigmatização e a discriminação a que eles têm sido vítimas, acabam por marginalizar (LEITE, 2000) e situar essas pessoas em vulnerabilidade socioambiental.

O quilombo de Mata Cavalo, de onde partem nossos estudos, situa-se em Nossa Senhora do Livramento, no estado de Mato Grosso. A região, que atraía exploradores de espécies vegetais, fauna nativa e, sobretudo, mineração, foi 


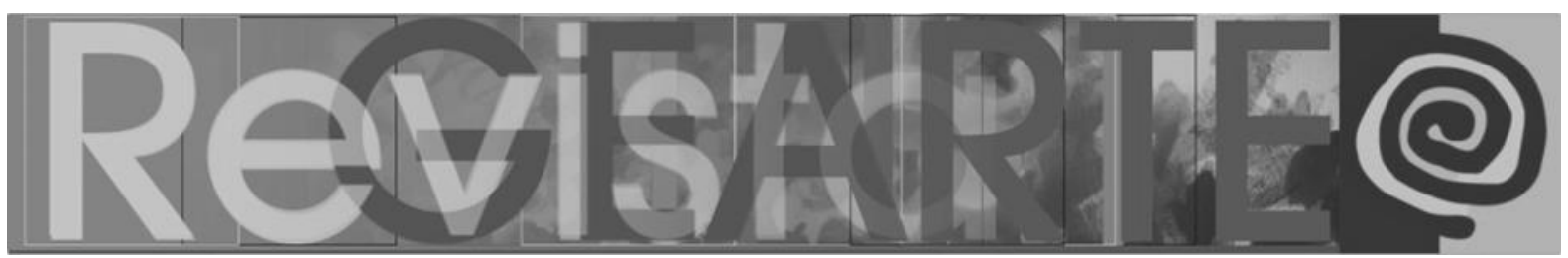

motivo de inúmeras disputas (SIMIONE, 2008). Esta comunidade se constitui no século XIX, a partir do momento em que D. Anna da Silva Tavares ratificou o testamento de seu falecido esposo (um antigo sesmeiro), para doar aos seus trinta e quatro escravos a área que fazia parte da sesmaria Boa Vida, e vendeu a um exescravo a sesmaria Mata Cavalos. Somente desta forma, naquela região, foi possível que se tornasssem proprietários de terras (BARROS, 2007).

Entretanto, as perseguições, humilhações e prisões permaneceram: além de serem expulsos de suas residências por fazendeiros, houveram inúmeras expropriações de terras quilombolas, por meio de ameaças e violências das mais diversas formas (BARCELOS, 2011). A regularização fundiária da região ainda não foi possível, e não há documentação definitiva junto ao INCRA (Instituto Nacional de Colonização e Reforma Agrária), o que evidencia ainda mais a situação de insegurança desta comunidade (MOREIRA, 2017).

Há mais de cem anos, Mata Cavalo têm sofrido ataques das classes hegemônicas: ainda que tenham se libertado do regime escravocrata há tempos, as constantes apropriações indevidas dos fazendeiros nas terras quilombolas, a degradação e contaminação dos rios por conta dos garimpos ainda existentes, o desmatamento da vegetação nativa, ocasionada pela expansão do agronegócio. Além disso, o descaso do poder público faz com que, muitas vezes, faltem condições mínimas de saúde, habitação, transporte e saneamento básico.

A educação escolarizada sempre passou por inúmeras dificuldades em infraestrutura, e sobretudo a interferência do racismo contra crianças e professsoras. Locais improvisados e precários, sempre foram muito comuns, no contexto escolar (Figura 1). Contudo, diante de tantas dificuldades, Senra (2009) afirma que, por todos os espaços escolares constituídos neste quilombo, aconteciam as articulações coletivas da comunidade: além das atividades pedagógicas, sempre houveram mobilizações festivas, religiosas, formações políticas e organização de reivindicações, fortalecendo outras educações, de cunho popular. 


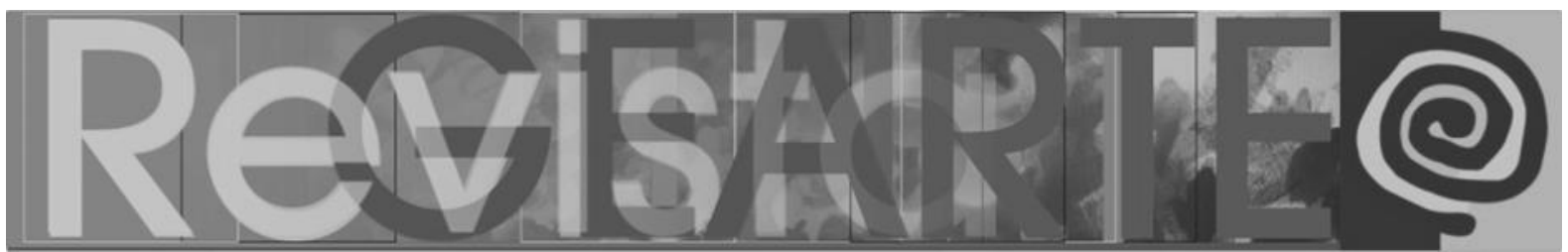

Figura 1 - Escola Municipal São Benedito. Associação Mata Cavalo de Baixo, Quilombo de Mata Cavalo, 2009.

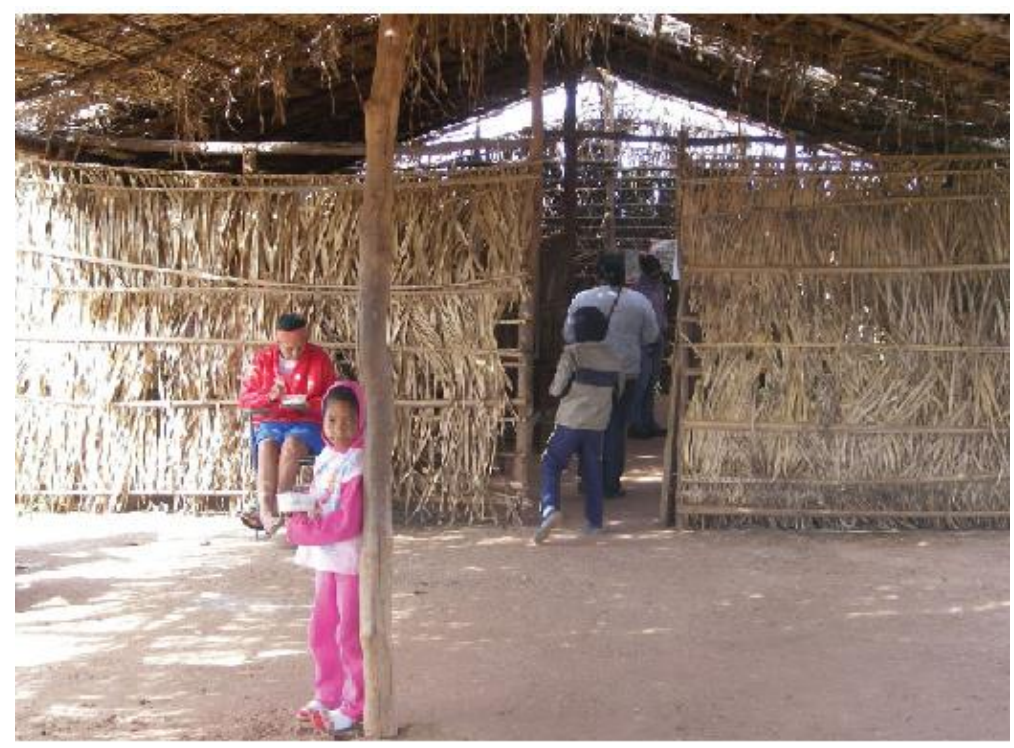

Fonte: Ronaldo Senra (2009).

Soares (2018) ressalta que são nestes locais em que acontecem as rodas de conversa e a reunião de grupos, na produção de artesanato e comidas regionais, para as datas festivas e outros momentos relevantes para a comunidade. Desta forma, se fortalecem os costumes ancestrais do quilombo, por meio da aprendizagem comunitária, por onde florescem a arte, a cultura, a fé e a esperança na luta por melhores condições de vida.

\section{A escola como território de lutas e esperanças}

Nossas dimensões do conceito de cultura são distantes das atribuídas pelas hierarquias e dicotomias impostas pelo sistema colonialista, as quais promovem a hierarquização e separação entre brancos e negros, e seus respectivos hábitos. Acreditamos no hibridismo entre os aspectos culturais, acolhendo diferenças (BHABHA, 1998), pois "a identidade cultural é o interesse central e significa necessidade de ser capaz de reconhecer a si próprio, ou, finalmente, uma necessidade básica de sobrevivência e de construção de sua própria realidade" (BARBOSA, 2004, p.1). 


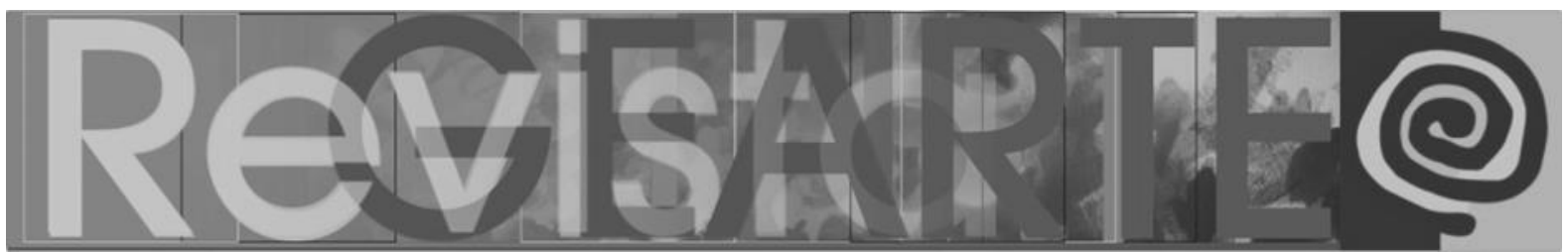

Esta comunidade, atualmente, é subdividida em seis associações independentes: Ponte da Estiva, Mata Cavalo de Baixo, Mata Cavalo de Cima, Mutuca, Aguassú e Capim Verde, cada uma com suas particularidades, afinidades e conflitos. Ao longo do tempo, as escolas já passaram por diversas localidades, sempre com muitas dificuldades de permanência, acesso e estrutura.

No ano de 2012, foi fundada a Escola Estadual Tereza Conceição de Arruda (Figura 2), na região de Mata Cavalo de Baixo. Este nome surgiu em uma homenagem à primeira professora deste quilombo, que foi uma importante liderança na luta pelos direitos ao estudo escolarizado para a comunidade (MANFRINATE, 2011).

Figura 2 - Escola Estadual Tereza Conceição de Arruda. Associação Mata Cavalo de Baixo, Quilombo de Mata Cavalo, 2017.

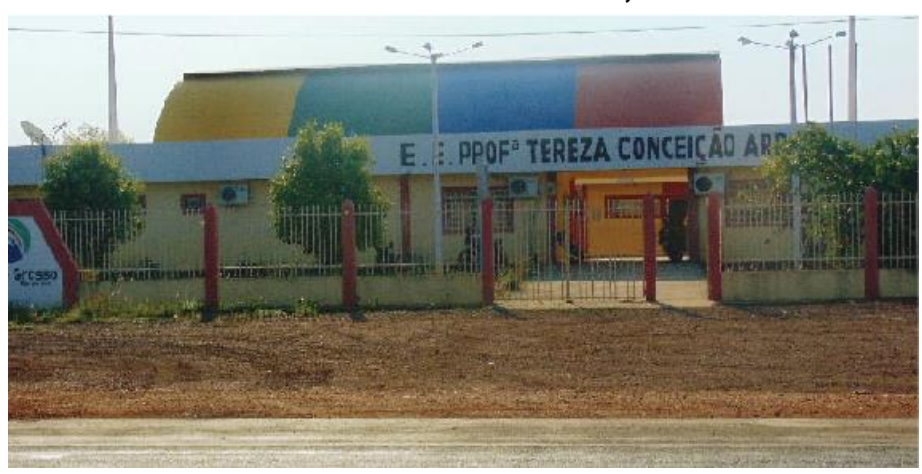

Fonte: Acervo das autoras (2017).

Neste ambiente, abriram-se novas possibilidades de articulação dos quilombolas, em busca de seus direitos e reivindicações. Nestas partilhas da vida, foi possível mapear as mais evidentes manifestações de arte e cultura da região.

Desde as primeiras visitas no espaço escolar, muito nos chamou atenção os detalhes da identidade cultural quilombola, como por exemplo, as máscaras africanas, dispostas no pátio da escola, produzidas manualmente pelos estudantes, professores e membros da comunidade, utilizando cascas de coqueiro como matéria-prima. Conforme Freire (1975), a cultura popular relaciona o ser humano com a natureza e a cultura, em uma dimensão que valoriza as práticas do 


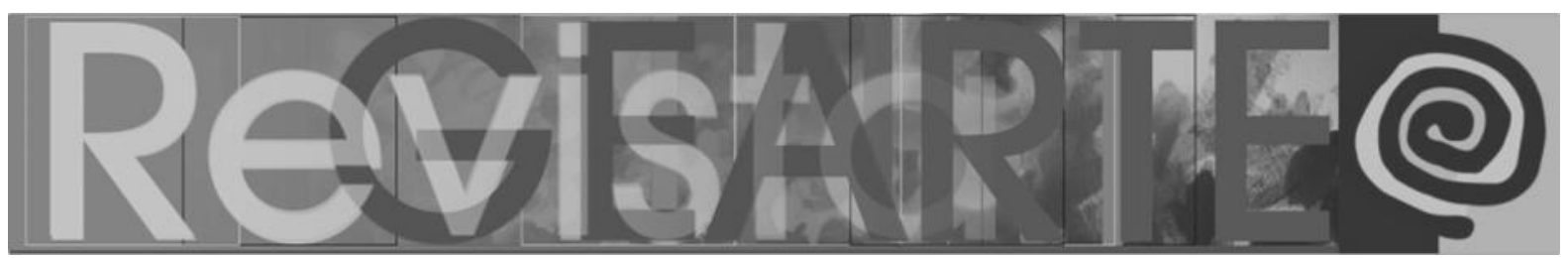

trabalho e seu potencial de transformação, em uma visão estimuladora de debates motivadores e críticos.

Ao lado da escola, situa-se a Casa da Cultura Quilombola de Mata Cavalo (Figura 3), inaugurada em 2015, edificada pela comunidade com o apoio de professores, estudantes universitários e financiamento de ONGs. Esta espécie de casa-museu foi a materialização de um desejo antigo dos quilombolas, resultante de um processo formativo que promoveu debates acerca da educação ambiental, visibilidade política e cultural. Foi construída aos moldes dos ancestrais escravos e quilombolas. Sob o chão batido de cupinzeiro, foram erguidas as paredes de adobe, preenchidas com barrote (pau-a-pique). $O$ teto estruturado por troncos de madeira, sustenta uma cobertura de lona, acomodando um telhado de grama, alimentado por uma cisterna, que direciona a água da chuva armazenada em uma caixa d'água (SILVA, 2015).

Figura 3 - Casa da Cultura Quilombola de Mata Cavalo. Associação Mata Cavalo de Baixo, Quilombo de Mata Cavalo, 2017.

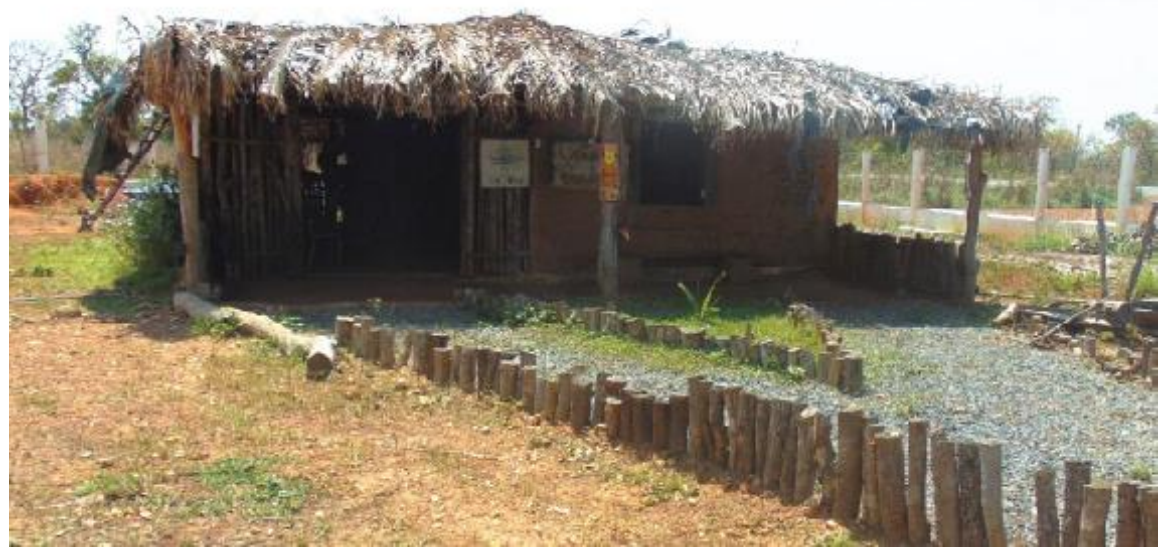

Fonte: Acervo das autoras (2017).

Esta casa abriga uma infinidade de artefatos antigos, como utensílios domésticos e de trabalho, instrumentos de tortura e prisão do tempo dos escravos, fotografias de festas culturais, esculturas de cerâmica, indumentárias utilizadas nas danças, além dos objetos produzidos manualmente com palha trançada, fibras de coqueiro, retalhos de tecido e telhas pintadas, ilustradas com motivos ligados à imagética africana e quilombola. 


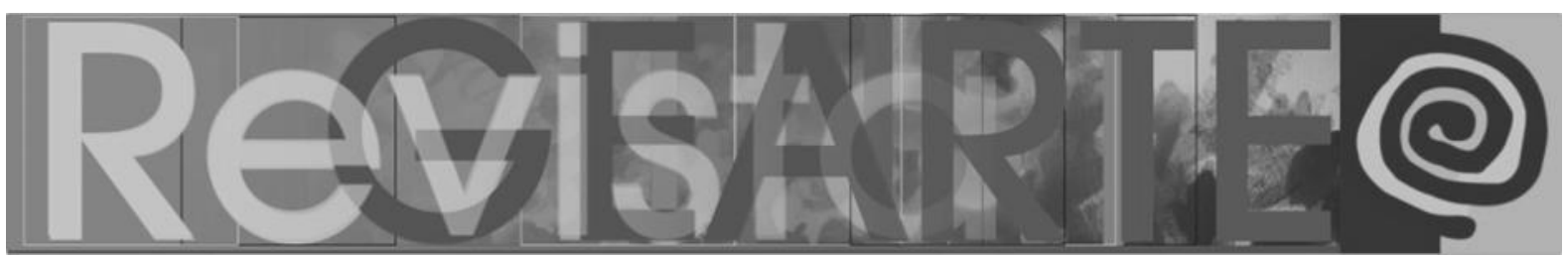

No sentido de promover a apreciação, o fortalecimento e o reconhecimento da cultura local, em uma contraposição ao poder hegemônico colonialista (BARBOSA, 2004), este local tem um importante papel nas práticas de arte/educação, pois ali os estudantes interagem e realizam atividades escolares, revisitando toda a ancestralidade quilombola, que ali foi materializada.

A valorização cultural está presente em todos os cantos da escola, desde as paredes pintadas manualmente, com frases de combate ao racismo e valorização da cultura negra, representada por desenhos de pessoas de referência na luta deste quilombo. Neste sentido, foi percebido que as práticas culturais não se restringem a datas comemorativas, como costuma ocorrer em grande parte das escolas, estando presentes em todos os momentos.

A cultura quilombola é pauta de constantes discussões, reuniões e processos formativos, e os debates acerca da visibilidade permeiam até mesmo nos cursos profissionalizantes e oficinas de arte promovidas no local. Neste sentido, o espaço escolar se tornou território fecundo para pesquisas e práticas artísticas e culturais, enquanto formas de resistência frente à opressão sofrida por este grupo social em situação de vulnerabilidade socioambiental.

\section{Mapeando cultura e arte no quilombo}

O presente artigo tem como objetivo discutir o ensino de arte e cultura em Mata Cavalo, junto à produção artesanal e as atividades coletivas, que afrontam a hegemonia capitalista das classes dominantes. Estes diálogos foram desenhados junto à esta comunidade, por um período de pesquisa de campo. Durante as observações e diálogos, foi possível compreender aspectos relevantes no cotidiano escolar, que relacionam a valorização da cultura quilombola, o ensino da arte e as práticas de arte/educação.

Em busca de nos desvencilhar dos habituais posicionamentos de estigmatização e folclorização que os quilombos têm sofrido (LEITE, 1999) 


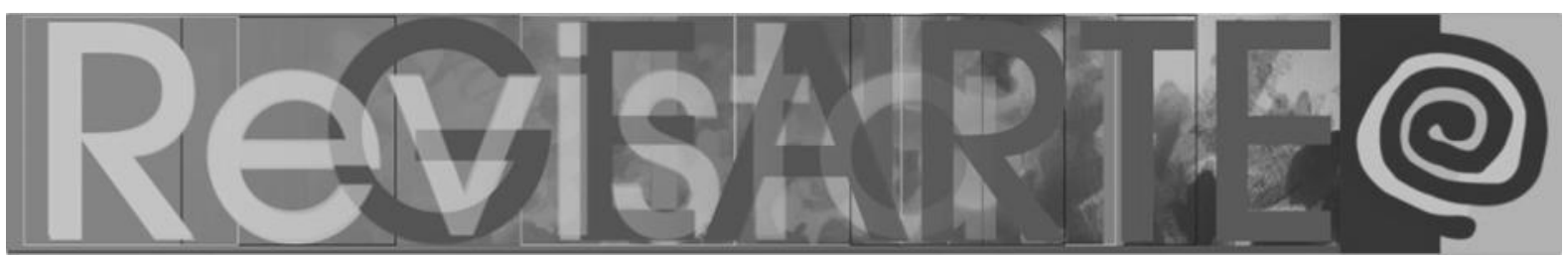

evidenciamos, a valorização dos diálogos como aspectos enriquecedores no reconhecimento da diversidade cultural, realizando leituras imagéticas, integradas no cotidiano e na história quilombola (BARBOSA, 1989; 2004).

Uma das propostas da arte-educação reside em fortalecer a herança artística e estética dos estudantes, considerando o ambiente em que vivem, permitindo a influência dos movimentos de arte comunitária (BARBOSA, 1989). Sato e Passos (2009) dentre reflexões, práxis e pesquisas em educação ambiental, especialmente voltadas a grupos sociais identitários, entendem como indissociável a relação entre arte, educação e ambiente, e conceberam a terminologia arteeducação-ambiental, no sentido de destacar a importância da imagética na interação entre os aspectos da cultura e natureza.

Os caminhos metodológicos percorridos neste território, consubtanciaramse no Mapa Social. Buscamos o fortalecimento das táticas de resistência, a defesa do território e o enfrentamento dos conflitos socioambientais (SILVA, 2011). Cartografamos as dimensões dialógicas, privilegiando as autonarrativas da comunidade, para dar visibilidade às multiplicidades do quilombo, por meio de diálogos informais, entrevistas e oficinas de mapeamento social, onde as dimensões das práticas cooperativas e artesanais, acabam por fortalecer o sentido da valorização quilombola, nos mais diversos contextos socioculturais.

Ao esboçar a relação que a comunidade estabelece entre a cultura e a natureza, buscamos diálogos que evidenciassem a arte, na sensibilização quanto aos impactos ambientais sofridos pelos quilombolas, ao longo de todos os anos de luta e resistência que eles têm estabelecido em seu território, conforme os preceitos da arte-educação-ambiental (SATO; PASSOS, 2009; SOARES, 2018).

Portanto, o processo de pesquisa que envolveu a concepção deste artigo, foi também desenhado, sob a forma de mapas pictóricos (FIORI; ALMEIDA, 2005), elaborados de forma participativa, com a comunidade. A posterior interpretação destes mapas, conectadas às autonarrativas, foram a base para a elaboração de 


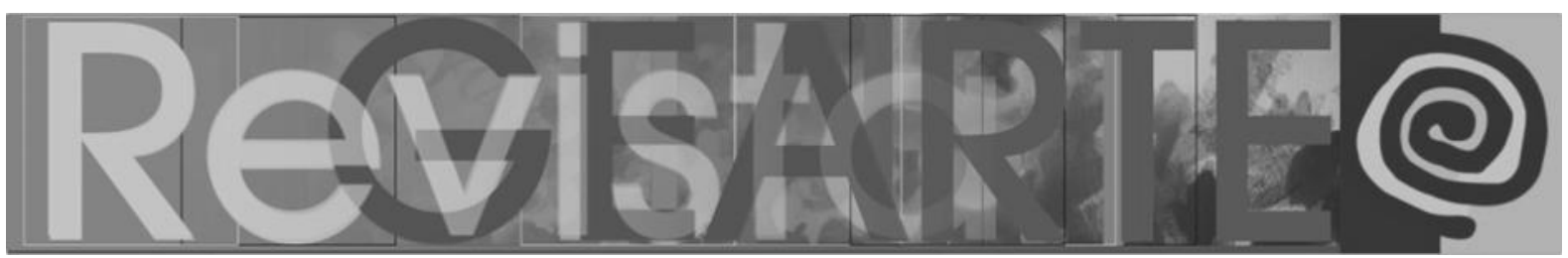

mapas sociais da cultura quilombola de Mata Cavalo. Embora os mapas sejam retratos temporários e limitados, diante da imensidão da arte e da cultura, nos fazem conhecer as práticas vivenciadas e as dificuldades na manutençao dos hábitos ancestrais.

O estímulo às cooperações dialógicas promovem a circularidade entre o fazer e o pensar, fortalecidas pela dimensão das práticas coletivas e artesanais (SENNET, 2015). Nos mapeamentos participativos elaborados junto à comunidade, foram levantadas importantes dimensões: os marcos históricos, as expressões artísticas, as comidas típicas e as festas, sendo fundamentais para identificar a arte/educação no contexto quilombola, bem como a importância das atividades de produção cultural e artesania.

A valorização das autonarrativas e autodenominações da comunidade, em si, já representam uma lógica contrária à hegemonia colonial (SILVA, 2011). No que tange aos marcos históricos desta comunidade, foram sinalizados vestígios do tempo de escravidão e tortura, os quais representam evidências materiais da violência: vestígios de senzalas, antigas fornalhas, pelourinho, e cemitérios, sendo que o mais antigo deles, se encontra dentro de uma fazenda, limitando o acesso quilombola a um importante espaço cultural é limitado.

No que se refere às expressões artísticas, foram os temas que instigaram intensos debates e impulsionaram as presentes narrativas, pois transitam com muita intensidade no ambiente escolar. A produção de artes plásticas, artesanato, os instrumentos musicais e danças típicas regionais foram bastante evidenciados.

Conforme as Orientações Curriculares das Diversidades Educacionais voltadas ao ensino no estado de Mato Grosso (2012), são necessárias as discussões acerca da realidade social e cultural das comunidades quilombolas. Desde a implantação destas diretrizes, os referenciais específicos para o aprendizado das Ciências e Saberes Quilombolas foram colocados em prática na escola de Mata Cavalo, mesmo com limitações de recursos materiais, e muito temos 


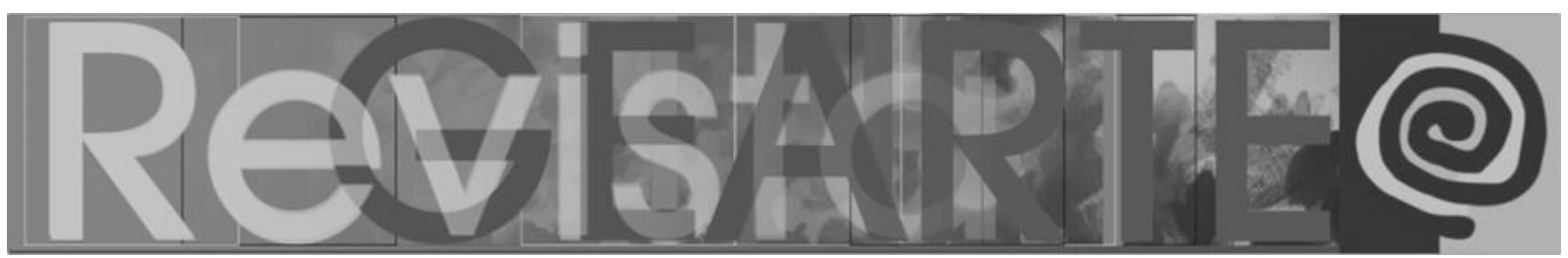

observado, em termos de produções artísticas, nesta comunidade, coadunando com Sennet (2015), o qual afirma que as ferramentas imperfeitas e incompletas estimulam a imaginação a desenvolver habilidades de reparo e improviso.

Para atender a estas especificidades educacionais do currículo quilombola, a escola procura planejar as aulas de Arte, juntamente com uma das disciplinas que compõem a parte diversificada: as Práticas em Cultura e Artesanato Quilombola (PCAQ), sendo uma das que mais têm obtido resultados significativos.

As danças regionais mais lembradas foram o raqueado, o cururu, o siriri, a dança do congo, e especialmente a dança afro, que conserva fortes influências da cultura africana, ressignificadas nos passos e ritmo elaborados pela professora de arte, praticada pelos estudantes:

Os grupos de Dança Afro ainda resistem e se fortalecem nos espaços culturais e escolares, mesmo em meio a dificuldades, tentam fortalecer suas identidades de resistência e têm conquistado oportunidades de se apresentar nas festas da comunidade e em alguns eventos desta região. Fortalecido pelo vínculo com o espaço escolar, o grupo de dança Hop Quilombola tem se destacado neste contexto cultural (SOARES, 2018, p. 108).

Neste sentido, o envolvimento dos estudantes e de toda a comunidade escolar com o grupo de dança Hop Quilombola (Figura 4) é significativo.

Figura 4 - Apresentação do grupo de dança Hop Quilombola, na Feira de Artes da escola. Associação Mata Cavalo de Baixo, Quilombo de Mata Cavalo, 2017.

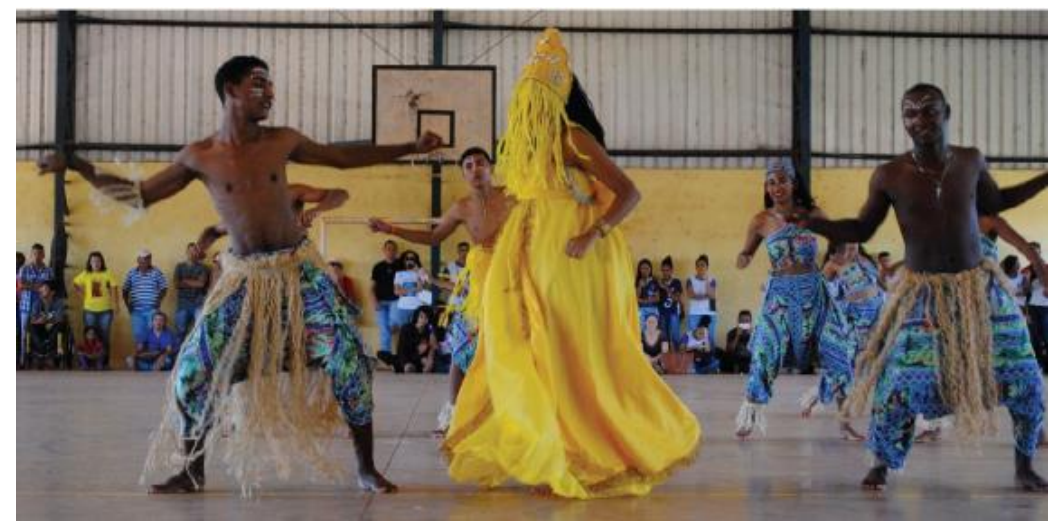

Fonte: Célia Soares (2017).

SOARES, Cristiane Carolina de Almeida; SILVA, Regina Aparecida da; SATO, Michèle Tomoko. 


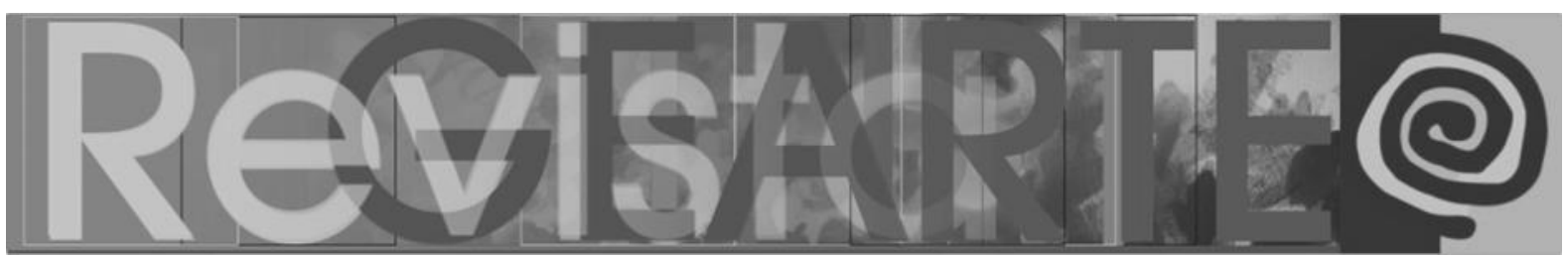

Para a elaboração dos figurinos, coreografias e melodias, há momentos de aula expositiva, contextualizando aspectos da história da África, observando práticas ancestrais quilombolas, as formas de expressão corporal e os aspectos que envolvem as danças afrobrasileiras. A produção deste grupo observa todos esses detalhes, na concepção de suas vestimentas, pinturas corporais e formas de configuração. Embora as apresentações culturais do grupo, aconteçam com mais frequência em datas comemorativas, no período da pesquisa, o grupo vinha realizando ensaios durante o ano todo.

Entretanto, as demais danças regionais, especialmente a dança do Congo (Figura 5), praticamente não acontecem mais no quilombo. Membros da comunidade explicam que o interesse dos jovens em aprender é praticamente inexistente, especialmente depois que o grupo que organizava os ensaios se desarticulou, com o falecimento de seu líder, Seo Cesáreo Sarate. As outras danças regionais acabam sendo praticadas somente nas datas festivas, e muitas, vezes, necessitam da ajuda de grupos pertencentes a outros quilombos, para organizar ensaios e apresentações.

Figura 5 - Homens realizando a Dança do Congo, nas ruas de Nossa Senhora do Livramento. Nossa Senhora do Livramento, 2010.

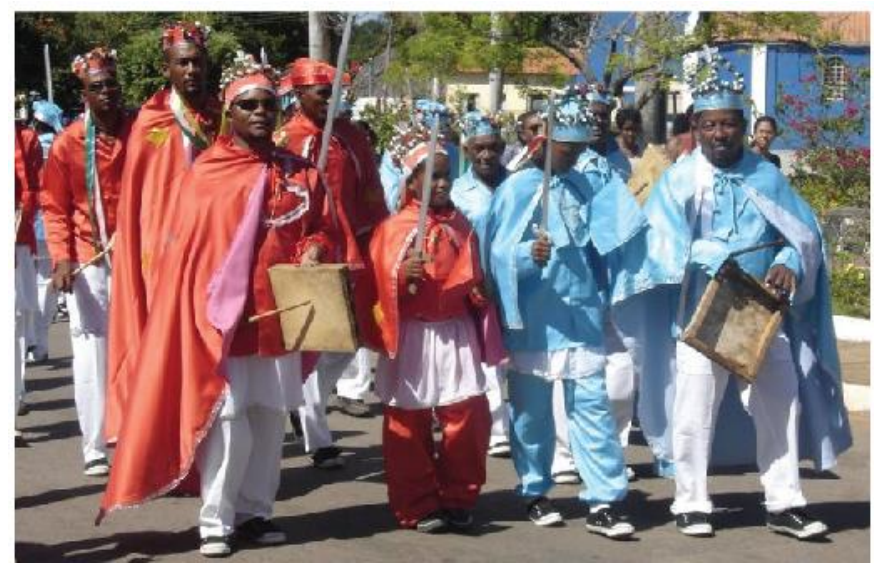

Fonte: Herman Hudson Oliveira (2010).

Devido a ausência de um local apropriado para a produção de artesanato das associações de moradores do quilombo, o espaço escolar acabou permanecendo como uma referência para receber os artesãos, onde as rodas de

SOARES, Cristiane Carolina de Almeida; SILVA, Regina Aparecida da; SATO, Michèle Tomoko. 20

A Arte/Educação no ambiente da escola quilombola de Mata Cavalo: cultura de diálogos e resistência. Revista GEARTE, Porto Alegre, v. 8, n. 1, p. 10-26, jan./abr. 2021.

Disponível em: http://seer.ufrgs.br/gearte 


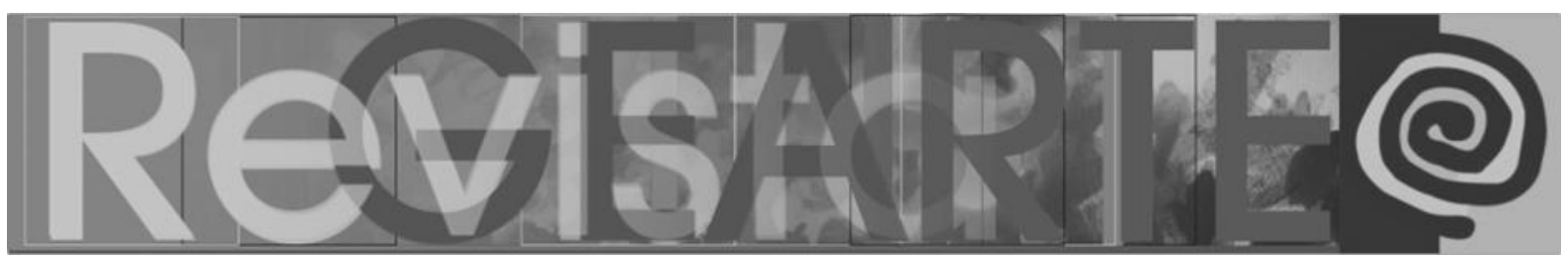

conversa acontecem, e as pessoas mais velhas da comunidade, procuram repassar os conhecimentos aos mais jovens. Brandão (1984) afirma que, por meio dos diálogos e vivências da educação popular, é possibilitada a valorização dos saberes populares, no sentido de promover a autonomia e a multiplicação dos conhecimentos, para além do espaço e do sistema escolarizado.

A produção dos artesanatos e alimentos para comercialização na região, acabam por estimular as atividades de economia solidária e da agricultura familiar, que realizam um contraponto à hegemonia capitalista, valorizando a produção associada e cooperada, entre os moradores da comunidade, na venda dos frutos da terra, coletados e preparados para serem comercializados, sevindo como forma de geração de renda (SILVA; CAETANO, 2000).

No entanto, boa parte do artesanato quilombola que se produz, acaba sendo destinado à Feira de Artes (Figura 6) na escola quilombola, que sempre acontece na semana de comemoração da Consciência Negra, no mês de novembro. É um momento importante para a comunidade, tanto para promover a visibilidade cultural, quanto para a venda de produtos. Este evento anual é bastante aguardado nesta região, pois acontecem as apresentações culturais, exposição de artes, venda de artesanato, sendo uma das atividades escolares em que os alunos também participam, apresentando trabalhos e participando de todos os preparativos, de forma coletiva. 


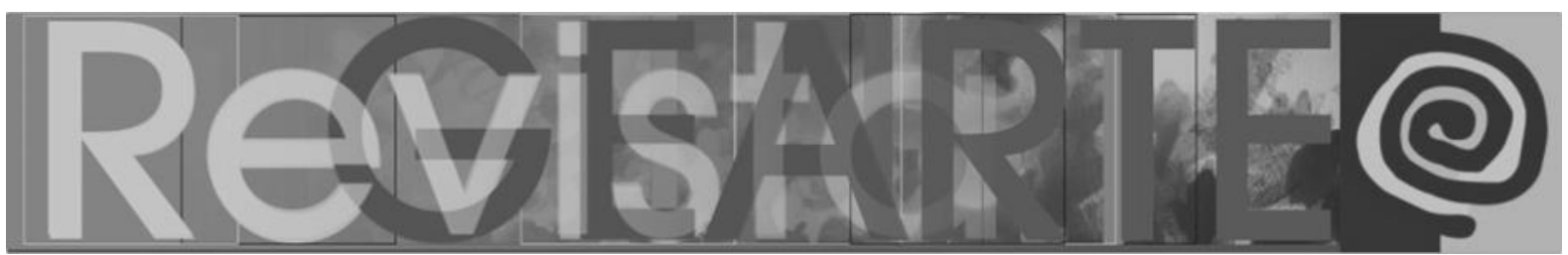

Figura 6 - Artesanatos e alimentos sendo vendidos na Feira de Artes. Associação Mata Cavalo de Baixo, Quilombo de Mata Cavalo, 2016.

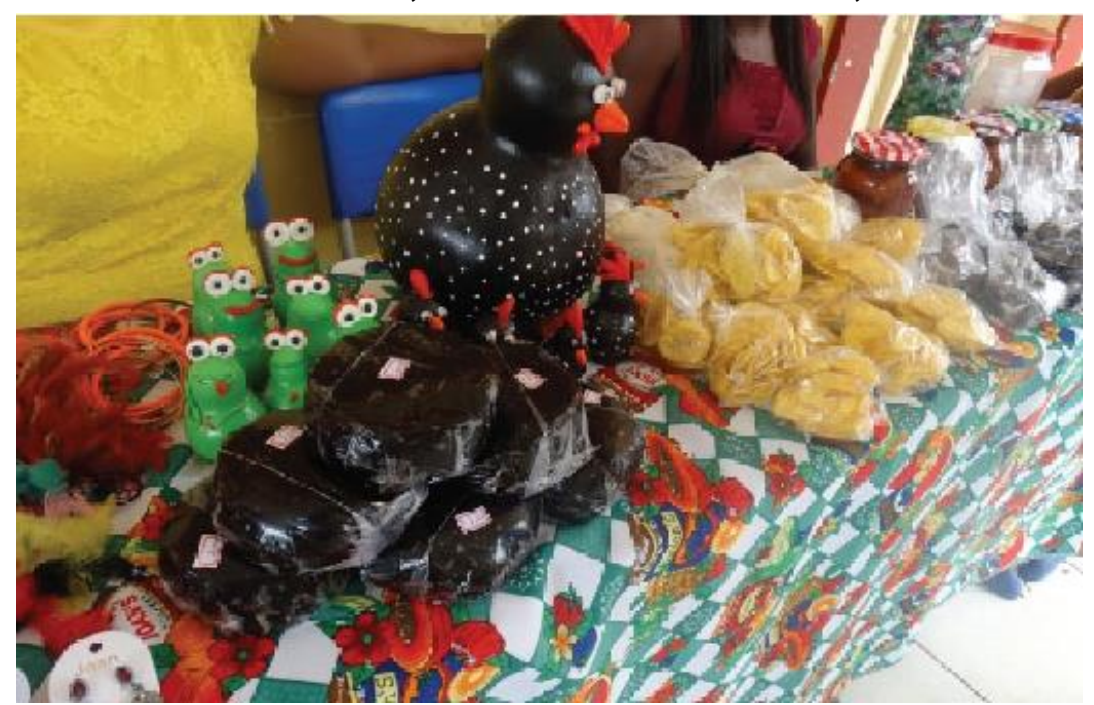

Fonte: Acervo das autoras (2016).

As comidas típicas, ainda que, algumas delas, estejam presentes na merenda escolar e nas datas festivas, aos poucos têm perdido muitos de seus ingredientes, devido a escassez da matéria prima necessária para sua preparação. O quilombo têm sofrido perdas irreparáveis, as quais interferem na subsistência, e nos modos de vida da comunidade.

Com os rios contaminados pelo mercúrio dos garimpos, quase não há peixes para o consumo. As queimadas e desmatamentos causados pela expansão do agronegócio, fizeram com que diversas espécies vegetais desaparecessem. Os pés de babaçu, por exemplo, cada vez mais difíceis de se encontrar, são muito importantes na alimentação e no fornecimento da palha, como matéria-prima de artesanato, utensilios domésticos e revestimento de telhado das casas populares. Além destas, há muitas outras espécies animais e vegetais, que fazem parte da cultura quilombola, mas que, atualmente, não existem mais em Mata Cavalo, por conta da intensa exploração no local.

Outro aspecto a se destacar são as festividades, em comemoração ao aniversário de pessoas de referência da comunidade, festas de santos, feiras culturais e outras que fazem parte do calendário quilombola. Por muito tempo, 


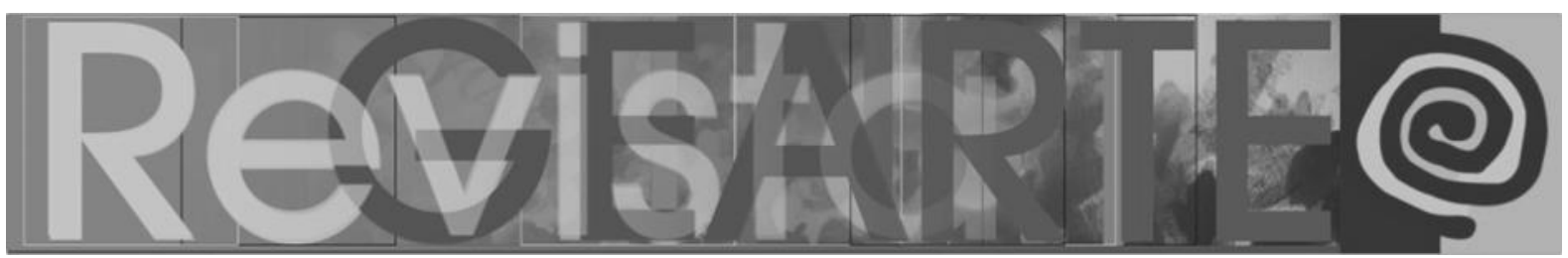

estas festas eram preparadas de forma coletiva, com o muxirum, definido pelos membros da comunidade como o momento de trabalhos colaborativos $e$ participativos, os quais costumam acontecer quando antecedem a preparação das festas. Nestes momentos coletivos, as relações de parceria se fortalecem, junto aos laços de cooperatividade e união, promovendo a articulação e o fortalecimento identitário do grupo (MOREIRA, 2017; NEVES; et al, 2011; SOARES, 2018).

Os trabalhos coletivos, que antecedem as datas festivas, constituem-se como um contraponto ao capitalismo vigente (KAWAHARA, 2015). Em tempos idos, a comida da festa era planejada coletivamente, desde o plantio dos alimentos que serviria como materia-prima para a fabricação dos bolos, farinhas e ensopados; a arrecadação do dinheiro para custear os itens da festa; o percorrer das rezas que antecedem as comemorações; os ensaios das danças e até mesmo a decoração artesanal dos andores, altares, barracas e bandeirolas, por todo espaço festivo. Contudo, estes momentos estão cada vez mais raros na comunidade, da forma como aconteciam outrora.

Antigamente, toda a comida era oferecida gratuitamente à população (desde o chá com bolo após a missa, ao amanhecer o dia, até o almoço e janta, durante a festa), muitas vezes, proveniente do pagamento de promessas aos santos. Atualmente, em boa parte das festas a alimentação é vendida, também com o objetivo de gerar renda para a comunidade, mas deixando de lado uma das tradições mais antigas do quilombo, que fortalece o sentido da coletividade.

\section{Considerações do caminho}

O mapeamento das manifestações da arte e da cultura quilombola, assim como a identificação de práticas de arte/educação, estão distantes de se restringir a uma descrição etnográfica. Elucidamos e consideramos, em grande medida, os debates acerca da visibilidade cultural e formas de resistência, de um povo que luta pela manutenção de seus hábitos ancestrais, mesmo em meio a tantas dificuldades. 


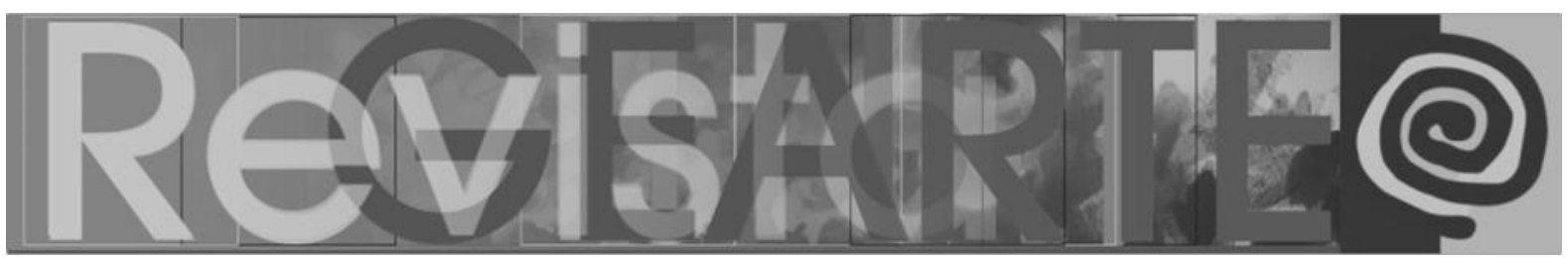

Os mapas participativos, atualmente servem como materiais de apoio pedagógico na escola, não somente pela variedade imagética que the foram atribuídos, mas por terem sidos confeccionados com e para esta comunidade. Neste sentido, foi percebida a apropriação dos estudantes, professores, gestores, moradores de Mata Cavalo, dos mais jovens aos mais antigos membros, como uma das formas de valorizar tudo aquilo que estas pessoas têm produzido, em meio a tantas lutas.

Ao evidenciar as práticas escolares, e sobretudo, a educação popular, que permeia este ambiente, desejamos também que a comunidade possa resistir cada vez mais ao poder hegemônico, incentivando que se apoderem de suas riquezas culturais, e possam se fortalecer junto à arte e à cultura quilombola.

\section{Referências}

BARBOSA, Ana Mae. Arte-Educação no Brasil: realidade hoje e expectativas futuras. Estudos avançados, São Paulo, v. 3, n. 7, p. 170-182, 1989. Disponível em: http://www.scielo.br/scielo.php ?script=sci_arttext\&pid=S0103-40141989000300010\&lng=en\&nrm=iso. Acesso em: 20 mai. 2020.

BARBOSA, Ana Mae. Arte, educação e cultura. Revista Textos do Brasil: educação para um desenvolvimento humano e social no Brasil, Itamaraty, Departamento Cultural, v. 7, 2004.

BARBOSA, Ana Mae. Arte/educação contemporânea: consonâncias internacionais. São Paulo: Cortez, 2005.

BARCELOS, Silvânio Paulo de. Quilombo Mata Cavalo: terra, conflito e os caminhos da identidade negra - Brasil. 2011. 221 f. Tese (Doutorado em História) - Programa de Pós-graduação em História, Universidade Federal de Mato Grosso, Cuiabá, 2011.

BARROS, Edir Pina de. Laudo Pericial Histórico-antropológico. Mato Grosso: Justiça Federal, 2007.

BHABHA, Homi K. O local da cultura. Belo Horizonte: Ed. UFMG, 1998.

BRANDÃO, Carlos Rodrigues. O que é Educação Popular. São Paulo: Brasiliense, 1984.

CASTILHO, Suely Dulce de. Culturas, família e educação na comunidade negra rural de MataCavalo-MT, 2008. 295 f. Tese (Doutorado em Educação: Currículo). Pontifícia Universidade Católica de São Paulo. São Paulo, 2008.

FIORI, Sérgio Ricardo; ALMEIDA, Regina Araújo. Cartografia Turística: uma Experiência com Mapas Pictóricos e Convencionais. In: X Encontro de Geógrafos da América Latina, 5., 2005, São Paulo, SP. Anais eletrônicos... São Paulo: 2005. Disponível em: http://docplayer.com.br/30355125-Cartografiaturistica-uma-experiencia-com-mapas-pictoricos-e-convencionais.html Acesso em 01 mai. 2020.

FREIRE, Paulo. Educação como prática da liberdade. 5. ed. Rio de Janeiro: Paz e Terra, 1975.

KAWAHARA, Lucia Shiguemi Izawa. Currículos Festeiros de Águas e Outonos: Fenomenologia da Educação Ambiental Pós-Crítica. 2015. 293 f. Tese (Doutorado em Educação) - Programa de Pósgraduação em Educação, Universidade Federal de Mato Grosso, Cuiabá. 


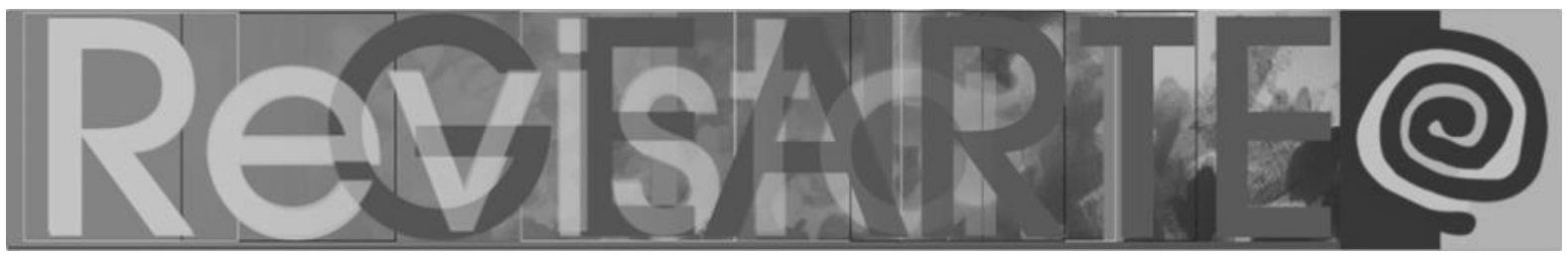

LEITE, Ilka Boaventura. Quilombos e quilombolas: cidadania ou folclorização? Horizontes Antropológicos, Porto Alegre, ano 5, n. 10, p. 123-149, 1999. Disponível em: <http://dx.doi.org/ 10.1590/S0104-71831999000100006>. Acesso em: 20 mai. 2020.

LEITE, Ilka Boaventura. Os quilombos no Brasil: questões conceituais e normativas. Etnográfica, Florianópolis, v. 4, n. 02, p. 333-354, 2000. Disponível em: <http://ceas.iscte.pt/etnografica/docs/v ol_04/N2/Vol_iv_N2_333-354.pdf.> Acesso em: 20 mai. 2020.

MANFRINATE, Rosana. Histórias femininas: poder, resistência e educação no Quilombo de Mata Cavalo. 2011. 150 f. Dissertação (Mestrado em Educação) - Programa de Pós-graduação em Educação, Universidade Federal de Mato Grosso. Cuiabá: 2011.

MATO GROSSO. Secretaria de Estado de Educação. Orientações Curriculares: Diversidades Educacionais. Cuiabá, 2012.

MOREIRA, Déborah Luíza. Território, luta e educação: dimensões pulsantes nos enfrentamentos dos conflitos socioambientais mapeados no Quilombo de Mata Cavalo. 2017, 162f. Dissertação (Mestrado em Educação) - Programa de Pós-graduação em Educação, Universidade Federal de Mato Grosso. Cuiabá: 2017.

MUNANGA, Kabengele. Origem e histórico do quilombo na África. Revista USP, São Paulo, n. 28 , p.58-63, dez-fev., 1996. Disponível em: http://dx.doi.org/10.11606/issn.2316-9036.v0i28p56-63. Acesso em: 25 mai. 2020.

NEVES, Camila; Emanuella Pereira; CAETANO, Edson; POLINI, Ilza Nunes da Cunha. Trabalho, educação e economia popular solidária: vivências no Mato Grosso. In: TORRES, Artemis; SEMERARO, Giovanni (Orgs.). Sobre saberes, educação e democracia. Cuiabá: EdUFMT, 2011. p. 33-56.

SATO, Michèle; PASSOS, Luiz Augusto. Arte-educação-ambiental. Ambiente \& Educação: Revista de Educação Ambiental, Rio Grande, v. 14, n. 1, p. 43-59, 2009. Disponível em: https://www.seer .furg.br/ambeduc/article/view/1136/446. Acesso em: 10 mai 2020.

SENNETT, Richard. O artífice. Trad. Clóvis Marques. 5. ed. Rio de Janeiro: Record, 2015.

SENRA, Ronaldo Eustáquio Feitoza. Por uma Contrapedagogia Libertadora no Ambiente do Quilombo Mata Cavalo. 2009. 137f. Dissertação (Mestrado em Educação) - Programa de Pósgraduação em Educação, Universidade Federal de Mato Grosso. Cuiabá: 2009.

SIMIONE, Roberta Moraes. Território de Mata Cavalo: Identidades em movimento na Educação Ambiental. 2008. 142f. Dissertação (Mestrado em Educação) - Programa de Pós-graduação em Educação, Universidade Federal de Mato Grosso. Cuiabá: 2008.

SILVA, Regina. Do invisível ao visível: o mapeamento dos grupos sociais do estado de Mato Grosso - Brasil. 2011. 221 f. Tese (Doutorado em Ciências) - Programa de Pós-graduação em Ecologia e Recursos Naturais, Universidade Federal de São Carlos. São Carlos: 2011.

SILVA, Regina. Inauguração da Casa da Cultura da Comunidade Quilombola de Mata Cavalo. GPEA-UFMT, Cuiabá, nov. 2015. Seção Escolas Sustentáveis. Disponível em: https://gpeaufmt. blogspot.com/search?q=casa+da+cultura Acesso em: 29 mai. 2020.

SILVA, Marilia de Almeida; CAETANO, Edson. A formação da cultura de resistência e a experiência de luta na produção de saberes. Horizontes, Cuiabá, v. 33, n. 1, p. 151-162, jan-jun. 2000. Disponível em: <https://revistahorizontes.usf.edu.br/ horizontes/article/view/52/71>. Acesso em: 25 mai. 2020.

SOARES, Cristiane Carolina de Almeida. Educação ambiental na comunidade quilombola de Mata Cavalo: diálogos da arte, cultura e natureza. 2018. 193f. Dissertação (Mestrado em Educação) Instituto de Educação, Universidade Federal de Mato Grosso, Cuiabá, 2018. 


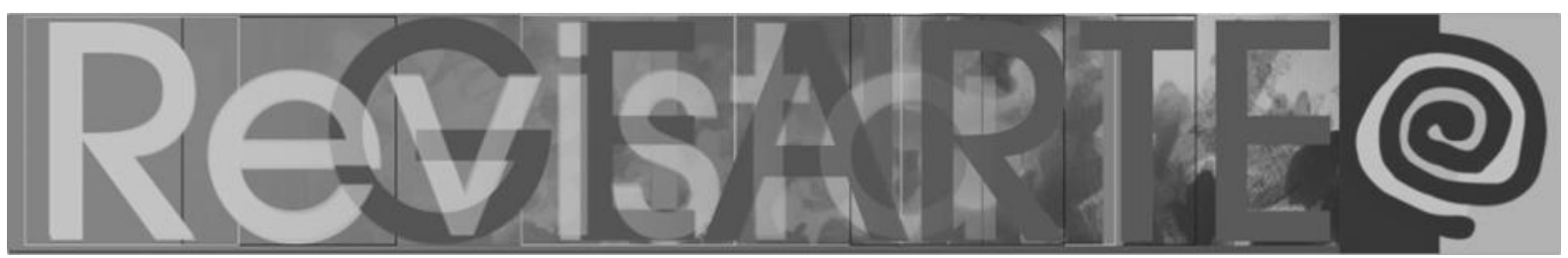

QUADROS, Imara Pizzato. Arte Popular: trilheira para arte/educação ambiental. In: SATO, Michèle (Org.). ECO-AR-TE para o encantamento do mundo. São Carlos: RIMa; FAPEMAT, 2011. p. 52-61.

\section{Cristiane Carolina de Almeida Soares}

Arte-educadora, professora e artista plástica. Trabalha com produção e facilitação de cursos de artesanato e artes visuais. É bacharel em Comunicação Social, com licenciatura em Artes Visuais, pós-graduada em MBA - Gestão de Marketing, mestra e doutoranda em Educação pela UFMT. Coordena o projeto de arte Pedra Papel e Tesoura e faz parte do GPEA-UFMT (Grupo Pesquisador em Educação Ambiental, Comunicação e Arte). Pesquisadora de educação ambiental, cultura popular, educação popular, arte-educação-ambiental, fluxos migratórios e colapsos climáticos.

ORCID: https://orcid.org/0000-0003-4359-9829

E-mail: pedrapapeletesoura@gmail.com

Lattes: http://lattes.cnpq.br/2926409951080865

\section{Regina Aparecida da Silva}

Possui graduação em licenciatura em ciências biológicas e mestrado em Educação pela Universidade Federal de Mato Grosso (UFMT), doutorado em Ciências pelo Programa de PósGraduação em Ecologia e Recursos Naturais (PPGERN) da Universidade Federal de São Carlos (UFSCar) (2011) e pós-doutorado em Educação pela UFMT (2013). É professora do departamento de Educação, Campus Universitário de Rondonópolis, UFMT. E, professora credenciada ao Programa de Pós-Graduação em Educação (PPGE/UFMT), pesquisando e orientando na área de educação ambiental, educação popular, movimentos sociais, mapa social e políticas públicas. Participa do Grupo Pesquisador em Educação Ambiental, Comunicação e Arte (GPEA). É vice coordenadora do GT 22 - Educação Ambiental - da Associação Nacional de Pós-Graduação e Pesquisa em Educação (ANPED).

ORCID: https://orcid.org/0000-0002-2207-8437

E-mail: rasbio@gmail.com

Lattes: http://lattes.cnpq.br/9329485783404187

\section{Michèle Tomoko Sato}

Licenciada em Ciências Biológicas (São Paulo: 1982), mestre em Filosofia (Norwich: 1992), doutora em ciências (São Carlos: 1997), pós-doutorado em Educação (Canadá, 2007), pós-doutorado em educação (Espanha, 2014). É docente titular no Programa de Pós-Graduação em Educação na Universidade Federal de Mato Grosso (UFMT) e pesquisadora do Grupo Pesquisador em Educação Ambiental, Comunicação e Arte (GPEA). Principais áreas de atuação: educação ambiental, artes, emergência climática, direitos humanos, migração climática e epistemologia popular. É coordenadora da Rede Internacional de Pesquisadores em Educação Ambiental e Justiça Climática (REAJA), envolvendo 5 países e 17 entidades.

ORCID: https://orcid.org/0000-0001-9834-4642

E-mail:michelesato@gmail.com

Lattes: http://lattes.cnpq.br/9264997837722900

Recebido em 14 de junho de 2020 Aceito em 12 de fevereiro de 2021 